\title{
Ureteroscopy and Intracorporeal Lithotripsy for Ureteric Stones: Stenting or not - A Prospective Randomized Study
}

\author{
A B M Golam Robbani ${ }^{1}$, P K Biswas ${ }^{2}$, S M Rakibul Alam ${ }^{3}, \mathrm{~K}$ M Abu Jalal ${ }^{4}$, M A Momen $^{5}$
}

\begin{abstract}
With the advancement of endourology, ureteric stones are mostly managed by intracorporeal lithotripsy via ureteroscopes, or by extracorporeal lithotripsy. Placement of ureteric stent is almost a routine after ureteric stone lithotripsy. Though stenting is necessary to prevent some post-operative complications, especially in difficult and complicated lithotripsy, it is associated with some morbidity as well. This study was carried out to compare the complications of the patients with or without stenting after uncomplicated ureteroscopic removal of ureteric stones.
\end{abstract}

50 patients with ureteric stone, amenable to ureteroscopic management, were prospectively randomized into a stented (25) and an unstented (25) group. 9.5 or $8.5 \mathrm{Fr}$ ureteroscope was used for the procedures. Pneumatic lithotripter was used for stone fragmentation and stone $I$ fragments were removed by grasper or by dormia basket.

Symptom questionnaires were completed by asking the patients after the procedures regarding the complication of flank pain, urinary symptoms and haematuria.

In this study, there was no statistically significant difference in age, stone size, or hospital stay between the groups $(p>0.05)$. Haematuria was more in stented than that of unstented group $(p=0.001)$. Flank pain and dysuria occur in both the groups without any significant difference. Frequency of micturation and lower abdominal pain developed more commonly in stented than that of unstented group. Operative duration is more in stented than that of unstented group but not significant statistically.

So, in our opinion, routine use of ureteric stent after uncomplicated ureteroscopic removal of ureteric stone is not necessary.

TAJ 2010; 23(1): 38-40

\section{Introduction}

With the invention of ESWL and ureteroscopy more than $95 \%$ of patients with ureteric stone are managed by these techniques ${ }^{1,2,3,4,5}$. ESWL is the accepted technique of managing stones in the urinary tract, especially of the kidney, worldwide. But endourological procedures have developed rapidly to remove stones from the urinary tract during the last decade ${ }^{2,3,5}$. Since the introduction of ureteroscopy, it has been established as a major additional method for treating ureteric calculi ${ }^{5,6}$. With the development of smaller and flexible ureteroscopes and new generation of various lithotripters, have made these procedures more safe and effective. Now, it is used for the stones both in the lower as well as for the upper urinary tract.

${ }^{1}$ Assistant Professor (c.c), Department of Surgery, Urology, Rajshahi Medical College, Rajshahi.

${ }^{2}$ Assistant Professor (c.c), Department of Surgery, Rajshahi Medical College, Rajshahi.

${ }^{3}$ Indoor Medical Officer, Department of Surgery, Surgery, Rajshahi Medical, College Hospital, Rajshahi.

${ }^{4}$ Indoor Medical Officer, Department of Surgery, Surgery, Rajshahi Medical College, Hospital, Rajshahi.

${ }^{5}$ Associate Professor, Department of Surgery, Surgery, Rajshahi Medical, College Hospital, Rajshahi 
Placement of a ureteric stent after ureteroscopy and stone extraction is a routine to prevent possible ureteric stenosis or to decrease secondary pain caused by mucosal oedema. Furthermore, symptoms like haematuria, dysuria, or urinary frequency cannot be ignored, and thus we have investigated the need of stenting after uncomplicated ureteroscopic lithotripsy by comparing the symptoms of randomly selected groups of patients with or without stenting.

\section{Methods and Material}

During the period of January 2005 to March 2010, 186 patients with lower and mid-ureteric stone were managed by ureteroscopy and intracorporeal lithotripsy using pneumatic lithotripter in Rajshahi Medical College Hospital and in a government approved private nursing home in Rajshahi City. Out of these 186, 50 patients of "uncomplicated procedures" were included in this study. Out of these 50 patients, 25 were selected randomly for placement of ureteric stent and 25 were remained unstented and called "stented" and "unstented" group respectively. After removal of stone, symptom questionnaires regarding post-operative pain, haematuria and urinary symptoms were asked, recorded and then compared.

Urinalysis and culture were done before the procedure in all patients. All procedures were done under spinal anaesthesia. 1gm ceftriazone, intravenously, was given just after anaesthesia. 8.5 or 9.5 Fr ureteroscope and pneumatic lithotripter were used for stone visualization and fragmentation respectively. Stone cone was used in some cases to prevent upward migration of the stone. Stone or fragments were retrieved by grasper or by stone basket. $6 \mathrm{Fr}, 26 \mathrm{~cm}$ long D-J stent were placed in the stented group and stenting was not done in unstented group. When the ureteric orifice or the stone could not be accessed, or there was injury to the ureter or when stone migrated upward, the cases were excluded from this study. Urethral catheter kept for 24 hours. Stents were removed usually 10 to 15 days after the procedure in the stented group.

Post-operatively, information regarding flank pain, dysuria, urgency, lower abdominal pain, frequency of micturation, haematuria were collected from the patients and were recorded. T-test were used for statistical analysis with $p<0.05$ considered to be statistically significant.

\section{Results}

There were 25 patients in each stented and unstented group. Table-I shows the characteristic of the patients in the study.

Table-I : Characteristics of the patients in the study.

\begin{tabular}{lccc}
\hline Variables & $\begin{array}{c}\text { Stented } \\
\text { group }\end{array}$ & $\begin{array}{c}\text { Unstented } \\
\text { group }\end{array}$ & $P$ value \\
\hline $\begin{array}{l}\text { Number of patient } \\
\text { Age of patients in }\end{array}$ & $\begin{array}{c}18-65 \\
(35.6)\end{array}$ & $\begin{array}{c}21-64 \\
(36.2)\end{array}$ & $p>0.05$ \\
years (mean) & & & \\
Sex & 16 & 15 & $p>0.05$ \\
$\quad$ Male & 9 & 10 & $p>0.05$ \\
$\quad$ Female & & & \\
Side & 10 & 9 & $p>0.05$ \\
$\quad$ Right & 15 & 16 & $p>0.05$ \\
$\quad$ Left & & & \\
$\quad \begin{array}{l}\text { Site of stone } \\
\quad \text { Lower ureter }\end{array}$ & 21 & 20 & $p>0.05$ \\
$\quad$ Mid ureter & 4 & 5 & $p>0.05$ \\
$\begin{array}{l}\text { Operative duration } \\
\text { in minutes (mean) }\end{array}$ & $12-31$ & $9-27(14.6)$ & $p>0.05$ \\
\hline
\end{tabular}

Age range of the patients was 18 to 65 and 21 to 64 years respectively in stented and unstented group. Males were more than that of female in this study. Similarly, stones were more on the left side than that of right. We managed stones only in the lower and a few of the mid ureter as because our ureteroscopes were semirigid. Operative duration, as shown in table-I, is more in stented group as because some time was required for stenting after stone retrieval, but statistically it is not significant. Operative duration was calculated from access to the ureteric orifices to the complete removal of stone with or without stenting.

Table-II shows the post-operative symptoms of the patients with comparison between the groups. These symptoms were observed and recorded for the first week after the procedures.

Table-II: Post-operative symptoms of the patients.

\begin{tabular}{lccc}
\hline \multicolumn{1}{c}{ Symptoms } & $\begin{array}{c}\text { Stented } \\
(\mathrm{n}=25)\end{array}$ & $\begin{array}{c}\text { Unstented } \\
(\mathrm{n}=25)\end{array}$ & $P$ value \\
\hline Haematuria & 20 & 14 & $P<0.05$ \\
Painful urination & 18 & 20 & $P>0.05$ \\
Flank pain & 10 & 8 & $P>0.05$ \\
Increased frequency & 21 & 9 & $P<0.05$ \\
Lower abdominal pain & 17 & 8 & $P<0.05$ \\
\hline
\end{tabular}


Table-II shows that post-operative haematuria is significantly more in stented than that of unstented group though the complain of dysuria is almost same in both the groups. 10 and 8 patients developed flank pain postoperatively in stented and unstented group respectively and the difference is not statistically significant. Frequency of micturation and lower abdominal pain are more common in stented than that of unstented group.

\section{Discussion}

Stents are being used in upper urinary tract for more than 30 years in the treatment of renal and ureteric stones ${ }^{5,7}$. Recently stenting has been primarily used to treat urinary obstruction and the frequency of this use is increasing with the increase in ureteroscopic management of stones ${ }^{5}$. In cases of upper urinary tract obstruction, a ureteric stent is placed temporarily to stabilize the patient until definitive treatment is given.

A ureteric stent is routinely placed after ureteroscopic lithotripsy and stone removal. Its use is quite justified in cases of complicated ureteroscopy like ureteral injury, narrow ureteric orifice, migrated stone or residual stone fragments to prevent immediate and late postoperative complications $^{5,8-10}$. However, routine placement of a ureteric stent, especially in an uncomplicated procedure, is questionable ${ }^{9,10}$. This study tried to compare the frequency of immediate postoperative complications after uncomplicated ureteroscopic stone removal with or without placement of ureteric stent.

Indeed, stent may cause complications, e,g haematuria, painful urination, urgency, flank pain, lower abdominal pain, bacteriuria, infection, or the stent may migrate upward ${ }^{5}$. Moreover, if stent remains for a long time due to forgetfulness, there may be encrustation or stone formation. The other problems associated with stent are, extended operative duration and the patient must bear the burden and cost of stent removal ${ }^{3,5,8}$. The results of this study are similar to that of other published reports $^{1,3,4,5,8,10}$. We used pneumatic lithotripter for stone fragmentation. Some stones were small enough and they were removed intact by grasper or stone basket without any difficulty.

\section{Conclusion}

We think that routine use of ureteric stent after ureteroscopic stone removal, especially in uncomplicated procedure, is not necessary. It rather increases the frequency of postoperative complications and the patient have to come again and bear the trouble and cost of removal of the stent.

\section{References}

1. Mogensen P, Andersen JT. : Primary in situ extracorporeal shock wave lithotripsy for ureteral calculi. Scand J Urol Nephrol(Suppl), 1994; 157:159-63.

2. Hofbauer J, Tuerk C, Hobarth K, Hasun R, Marberger M. : ESWL in situ or ureteroscopy for ureteric stones? World J Urol, 1993; 11: 54-58.

3. Marberger M, Hofbauer J, Turk C, Hobarth $\mathrm{K}$, Albrecht W. : Management of ureteric stones. Eur Urol, 1994; 25 : 265-272.

4. Preminger GM. : Technique versus technology. What is the most appropriate method for the removal of ureteral calculi. J Urol, 1994; 152: 66-67.

5. Jeong $\mathrm{H}$, Kwak $\mathrm{C}$, Lee SE. : Ureteric stenting after ureteroscopy for ureteric stones: a prospective randomized study assessing symptoms and complications. BUJ Int, 2004; 93: 1035-1035

6. Lyon ES, Kyker JS, Schoenberg HW. : Transurethral ureteroscopy in women: a ready addition to the urological armamentarium. J Urol, 1978; 167: 859-860.

7. Zimskind PD, Fetter TR, Wilkerson JL. : Clinical use of long-term indwelling silicone rubber ureteral splints inserted cystoscopically. J Urol, 1967; 97: 840-844.

8. Stoller ML, Wolf JS Jr, Hofmann R, Marc B. : Ureteroscopy without routine balloon dilation : an outcome assessment. J Urol, 1992; 147: 1238-42.

9. Harmon WJ, Sershon PD, Blute ML, Patterson DE, Segura JW. : Ureteroscopy : current practice and long-term complications. J Urol, 1997; 157: 28-32.

10. Netto NR Jr, Joaquim de Almeida C, Esteves SC, Andrade EFM. : Ureteroscopic stone removal in the distal ureter. Why change? J Urol, 1997; 157: 2081-3. 